University of Nebraska - Lincoln

DigitalCommons@University of Nebraska - Lincoln

\title{
Microbial community analysis of swine wastewater anaerobic lagoons by next-generation DNA sequencing
}

Thomas F. Ducey

USDA-ARS, thomas.ducey@ars.usda.gov

Patrick G. Hunt

USDA-ARS

Follow this and additional works at: https://digitalcommons.unl.edu/usdaarsfacpub

Ducey, Thomas F. and Hunt, Patrick G., "Microbial community analysis of swine wastewater anaerobic lagoons by next-generation DNA sequencing" (2013). Publications from USDA-ARS / UNL Faculty. 1149. https://digitalcommons.unl.edu/usdaarsfacpub/1149

This Article is brought to you for free and open access by the U.S. Department of Agriculture: Agricultural Research Service, Lincoln, Nebraska at DigitalCommons@University of Nebraska - Lincoln. It has been accepted for inclusion in Publications from USDA-ARS / UNL Faculty by an authorized administrator of DigitalCommons@University of Nebraska - Lincoln. 
Molecular biology, genetics and biotechnology

\title{
Microbial community analysis of swine wastewater anaerobic lagoons by next-generation DNA sequencing
}

\author{
Thomas F. Ducey*, Patrick G. Hunt \\ ARS-USDA, CPSWPRC, 2611 West Lucas Street, Florence, SC 29501, USA
}

\section{A R T I C L E I N F O}

\section{Article history:}

Received 28 September 2012

Received in revised form

1 March 2013

Accepted 10 March 2013

Available online 26 March 2013

\section{Keywords:}

Anaerobic lagoon

Swine wastewater

Pyrosequencing

Microbial communities

\begin{abstract}
A B S T R A C T
Anaerobic lagoons are a standard practice for the treatment of swine wastewater. This practice relies heavily on microbiological processes to reduce concentrated organic material and nutrients. Despite this reliance on microbiological processes, research has only recently begun to identify and enumerate the myriad and complex interactions that occur in this microbial ecosystem. To further this line of study, we utilized a next-generation sequencing (NGS) technology to gain a deeper insight into the microbial communities along the water column of four anaerobic swine wastewater lagoons. Analysis of roughly one million 16S rDNA sequences revealed a predominance of operational taxonomic units (OTUs) classified as belonging to the phyla Firmicutes (54.1\%) and Proteobacteria (15.8\%). At the family level, 33 bacterial families were found in all 12 lagoon sites and accounted for between $30 \%$ and $50 \%$ of each lagoon's OTUs. Analysis by nonmetric multidimensional scaling (NMS) revealed that TKN, COD, ORP, TSS, and DO were the major environmental variables in affecting microbial community structure. Overall, 839 individual genera were classified, with 223 found in all four lagoons. An additional 321 genera were identified in sole lagoons. The top 25 genera accounted for approximately $20 \%$ of the OTUs identified in the study, and the low abundances of most of the genera suggests that most OTUs are present at low levels. Overall, these results demonstrate that anaerobic lagoons have distinct microbial communities which are strongly controlled by the environmental conditions present in each individual lagoon.
\end{abstract}

Published by Elsevier Ltd.

\section{Introduction}

The use of anaerobic lagoons for the passive treatment of swine wastewater remains a steadfast practice of a majority of confined animal feeding operations (CAFOs). These systems rely primarily on microbial activity to reduce organic material and nutrients. While the understanding of the microbial processes occurring in these lagoons has improved over time, there still remains much to be understood about the microbial communities - and their interactions - in these ecosystems. This understanding becomes even more critical when considering that these treatment systems continue to be heavily relied upon by the industry. Over the course of the past two decades, the number of swine operations has been reduced by more than $60 \%$, while the average number of swine per operations has more than quadrupled. Taken together, these two factors have resulted in an extreme concentration of swine wastewater in a constrained space that must be effectively treated and removed from these operations.

\footnotetext{
* Corresponding author. Tel.: +1 843669 5203; fax: +1 8436696970 .

E-mail address: thomas.ducey@ars.usda.gov (T.F. Ducey).
}

Research towards understanding microbiologically related aspects of anaerobic lagoon treatment has focused primarily on the following areas: (1) pathogens [1-4]; (2) nutrient cycling [5-9]; and (3) malodorous compounds [10-14]. The techniques used to address these issues have varied from study to study but have employed both direct culturing methods to isolate, identify, and enumerate bacteria [3,11], and a number of non-culturing molecular methods. The non-culturing molecular techniques include the following: (1) quantitative Real-Time PCR (qPCR) [7,15]; (2) denaturing gradient gel electrophoresis (DGGE) [5]; (3) fluorescent in situ hybridization (FISH) [9]; and (4) cloning and sequencing of 16S rDNA or process-specific genes [12,15]. To date however, no studies examining the microbial communities of anaerobic wastewater lagoons have utilized next-generation sequencing (NGS) technologies.

Next-generation sequencing technologies allow - via cost effective, extremely high-throughput sequencing - for deeper taxonomic resolution of microbial communities [16]. These technologies have been utilized to characterize a number of ecosystems $[17,18]$, and have been used to address scientific issues spanning from agriculture [19], the environment [20], to medicine [21]. Bringing these technologies to focus on the microbial communities 
of anaerobic wastewater lagoons would provide the most thorough look, to date, at these populations.

To this aim, we collected samples from four North Carolina anaerobic wastewater lagoons with varying chemical compositions. These samples were collected at three depths (surface $25 \mathrm{~cm}$, midway between surface and bottom, and $25 \mathrm{~cm}$ from the bottom) along the water column of these lagoons. We then utilized pyrosequencing of variable regions one through three $(\mathrm{V} 1-\mathrm{V} 3)$ of the bacterial 16S rDNA to measure each lagoons microbial community composition and diversity.

\section{Materials and methods}

\subsection{Site description and sample collection}

Four commercial swine lagoons (labeled L1 through L4) located in North Carolina were chosen for this study. Lagoons were divided into quadrants, and $1 \mathrm{~L}$ samples were collected from each of three points within the water column as follows: (a) $15 \mathrm{~cm}$ below the surface; (b) midway between surface and bottom (depth range: 70-101 cm); and (c) $15 \mathrm{~cm}$ off the lagoon bottom (depth range: 122-191 cm). Samples were collected using a telescopic jar sampler (Lab Safety Supply, Janesville, WI), and stored on ice and transported to the laboratory for analysis. These lagoons were either finish (L1), farrow (L4), or farrow to finish (L2 and L3) operations. Additionally, the lagoons varied in area as follows: 1.58 ha (L1); 2.68 ha (L2); 0.54 ha (L3); and 0.58 ha (L4). For the purposes of this study, lagoon sample naming conventions were based on sampling depth (T, top; M, middle; B, bottom).

\subsection{Wastewater analysis}

All wastewater analyses, which included biological oxygen demand (BOD), chemical oxygen demand (COD), total suspended solids (TSS), volatile suspended solids (VSS), ammonium $\left(\mathrm{NH}_{4}-\mathrm{N}\right.$ ), nitrite and nitrate $\left(\mathrm{NO}_{x}-\mathrm{N}\right)$, total nitrogen $(\mathrm{TN})$, Kjeldahl-N (TKN), orthophosphate- $\mathrm{P}\left(\mathrm{PO}_{4}-\mathrm{P}\right)$, total phosphorus (TP), and chloride (Cl) were performed according to Standard Methods for the Examination for Water and Wastewater [22]. Total organic carbon (TOC) analysis was performed on a Shimadzu TOC-VSCN (Shimadzu Corp., Kyoto, Japan). Dissolved oxygen (DO), electrical conductivity (EC), oxidative reductive potential (ORP), and pH were measured with a multiparameter $\mathrm{pH} / \mathrm{ORP}$ meter (YSI Inc., Yellow Springs, $\mathrm{OH}$ ).

\subsection{DNA extraction}

Prior to DNA extraction a composite sample, consisting of equal volumes from each of four quadrant samples taken at each lagoon depth, was generated as previously described [6]. From this composite sample, a volume of $5 \mathrm{~mL}$ was centrifuged at $14,000 \times \mathrm{g}$ for $5 \mathrm{~min}$, and DNA was extracted from the resultant pellet as described previously [23].

\subsection{Pyrosequencing of $16 S$ rDNA gene}

The 16S rDNA gene $\mathrm{V} 1-\mathrm{V} 3$ region was amplified by PCR using universal primers $8 \mathrm{~F}$ and $518 \mathrm{R}$ containing the Roche- $454 \mathrm{~A}$ or B titanium sequencing adapters. While it has been demonstrated that sample bias can be introduced during amplification of the $16 \mathrm{~S}$ rDNA gene [24], this region is recommended for use in NGS applications [25]. The V1-V3 region provides a dataset with deeper richness compared to other hypervariable regions [26], while at the same time providing a high degree of classification accuracy [27], and a low degree of classification bias towards specific taxonomic groups [28]. Amplification products were quantified using the Quant-iT
PicoGreen double-stranded DNA assay (Invitrogen) and quality controlled on an Agilent 2100 BioAnalyzer (Agilent). Pyrosequencing on a Roche Genome Sequencer GS-FLX was then performed as previously described by Martinez et al. [23] by the Center for Applied Genomics and Ecology (CAGE) at the University of Nebraska - Lincoln.

\subsection{Pyrosequence processing}

Raw data were filtered in order to remove sequences of poor quality [29]. Sequence reads with more than one ambiguous base or with an average quality score of $\geq 20$, as well as reads $>200$ nucleotide (nt) sequence length were excluded from downstream analysis. Sequence reads were then trimmed to remove adapter and primer sequences.

\subsection{Microbial community analysis}

Trimmed sequences were assembled and aligned into operational taxonomic units (OTUs), also referred to as phylotypes, in Geneious ver. 5.6.2 (Biomatters Ltd., Auckland, New Zealand) [30]. A minimum of two sequence reads, assembled together at a $97 \%$ sequence similarity threshold, were required for designation as an OTU. All sequences that failed to assemble at the $97 \%$ sequence similarity threshold were designated as singletons and removed from further phylogenetic analysis. The consensus sequences derived from each OTU were phylogenetically classified using the Ribosomal Database Project's (RDP) pyrosequencing pipeline. Rarefaction curves were calculated using Analytic Rarefaction ver. 1.3 [31]. Simpson's Index of Diversity $(1-D[32]$,$) was calculated$ where $D=\sum\left(n_{i}\left(n_{i}-1\right) / N(N-1)\right)$, with $n_{i}$ the proportion of a given taxon $(i)$, and $N$ representing the total number of sequence reads from an individual lagoon sample. Good's coverage [33] was calculated as $G=1-n / N$ where $n$ is the number of singletons based on a $97 \%$ sequence similarity threshold, and $N$ is the total number of sequence reads from an individual lagoon sample.

PC-ORD ver. 6 (MJM Software, Gleneden Beach, OR) was used to perform nonmetric multidimensional scaling analysis of bacterial communities found in each of the 12 sites. Comparisons were performed using relative abundances from phylotypes, grouped according to bacterial family, found in at least half of the sites. To avoid redundancy in the environmental data, single variables were selected to represent overlapping environmental data (see Table 3). Distribution of individual bacterial genera across the four lagoons was visualized using Venn diagrams compiled by the software package Venny [34].

\subsection{Nucleotide submissions}

All sequencing data, in compressed (.zip) format, can be downloaded from the following URL: https://www.ars.usda.gov/Services/ docs.htm?docid=23124.

\section{Results}

From the 12 lagoon sites that were assayed, a total of 987,606 high quality sequence reads were obtained (Table 1). These sequence reads were assigned to a total of 15,682 operational taxonomic units (OTUs). Each lagoon was covered by an average of $246,902( \pm 54,926)$ sequence reads and $3921( \pm 877)$ OTUs, with an average of $82,300( \pm 28,962)$ sequence reads, and 1307 ( \pm 371$)$ OTUs per site. Likewise, a total of 34,715 singletons remained, and accounted for between $2.3 \%$ and $5.9 \%$ of all sequence reads obtained per site. While rarefaction curves (Fig. 1) continued to trend upwards, a Good's coverage estimate of $96.5 \%( \pm 1.2)$ suggested that a 
Table 1

Sequencing information, based on depth, for each of four swine wastewater lagoons.

\begin{tabular}{llrlrll}
\hline Lagoon & Depth & \# Reads & OTUs $^{\mathrm{a}}$ & Singletons & Coverage (\%) & $1-D$ \\
\hline Lagoon 1 & Top & 79,482 & 1493 & $4725(5.9 \%)$ & 94.06 & 0.942 \\
& Middle & 54,299 & 1027 & $2958(5.4 \%)$ & 94.55 & 0.940 \\
& Bottom & 93,049 & 1202 & $3338(3.6 \%)$ & 96.41 & 0.931 \\
Lagoon 2 & Top & 131,959 & 2264 & $3779(2.9 \%)$ & 97.14 & 0.966 \\
& Middle & 85,767 & 1617 & $2362(2.8 \%)$ & 97.25 & 0.929 \\
& Bottom & 51,113 & 1264 & $1416(2.7 \%)$ & 97.23 & 0.881 \\
Lagoon 3 & Top & 78,360 & 1231 & $3778(4.8 \%)$ & 95.18 & 0.934 \\
& Middle & 105,995 & 1264 & $3733(3.5 \%)$ & 96.48 & 0.947 \\
& Bottom & 125,507 & 1260 & $4212(3.4 \%)$ & 96.64 & 0.919 \\
Lagoon 4 & Top & 62,264 & 1001 & $1530(2.5 \%)$ & 97.54 & 0.967 \\
& Middle & 37,322 & 782 & $974(2.6 \%)$ & 97.39 & 0.965 \\
& Bottom & 82,489 & 1277 & $1910(2.3 \%)$ & 97.68 & 0.964 \\
\hline
\end{tabular}

a Based on $97 \%$ similarity, excluding singleton sequence reads.

majority of the phylotypes present in the sites had been identified. Additionally, Simpson's reciprocal index of diversity $(1 / D)$ indicated that bacterial diversity decreased as a function of depth.

A total of 22 phyla or candidate divisions were represented amongst the OTUs classified in this study (Fig. 2A), with the vast majority $(81.2 \% \pm 3.0 \%)$ classified to one of four major phyla: Actinobacteria (7.2\%), Bacteroidetes (4.1\%), Firmicutes (54.1\%), or Proteobacteria (15.8\%). The phyla Chloroflexi (1.3\%) and Synergistetes $(2.5 \%)$ accounted for an additional $3.8 \%( \pm 1.2)$ of the studies OTUs. Four of the Proteobacterial classes $(\alpha, \beta, \delta$, and $\gamma)$ were represented in all 12 sites (Fig. 2B); OTUs classified as $\varepsilon$-proteobacteria were identified in 10 of the 12 sites, the exceptions being L1T and L4M. For Firmicutes, phylotypes belonging to the class Clostridia accounted for the majority of all classified OTUs $(83.6 \% \pm 6.3$; Fig. 2C).

At the family level, a total of 150 bacterial families were represented from sequences found in at least 1 of the 12 sites (Fig. 3 ). Only $33(22 \%)$ of these families were represented in all 12 sites, and 84 (56\%) were found to be in at least half of the sites examined in this study. The 33 families identified in all twelve sites account for over $50 \%$ of all phylotypes in L1, L2, and $\mathrm{L} 4(53.6 \% \pm 2.3)$ and $36.8 \%$ $( \pm 3.1)$ of the phylotypes in L3. In terms of abundance, the Ruminococcaceae were the best represented amongst the phlyotypes, with $15.2 \%( \pm 2.8)$ for $\mathrm{L} 1,18.4 \%( \pm 1.8)$ for $\mathrm{L} 2,6.2 \%( \pm 0.9)$ for $\mathrm{L} 3$, and $20.5 \%( \pm 0.5)$ for $\mathrm{L} 4$. Other well represented families from all twelve sites included the Clostridiaceae $(6.8 \% \pm 2.2)$, Lachnospiraceae

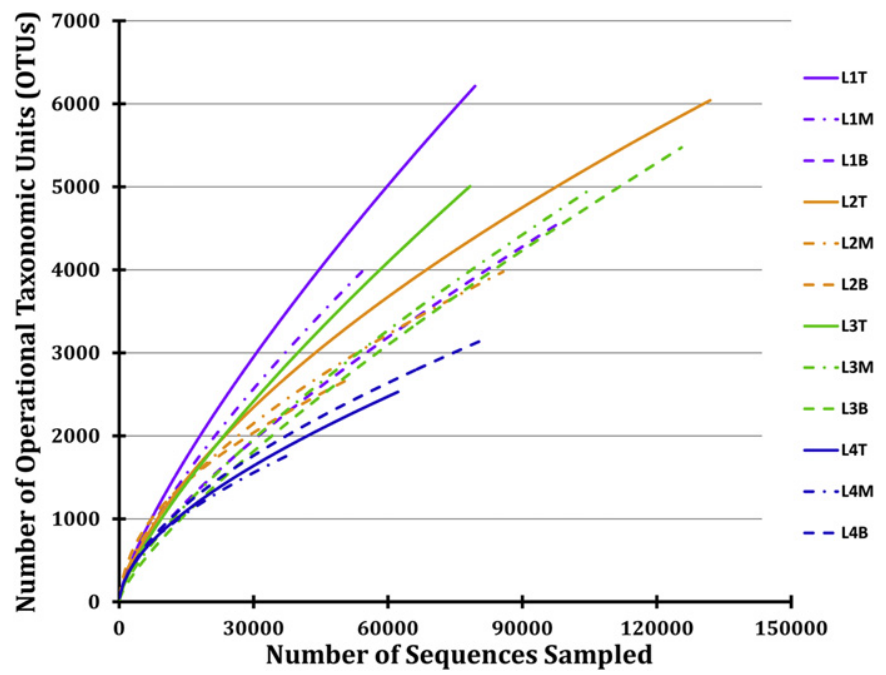

Fig. 1. Rarefaction analysis of bacterial $16 \mathrm{~S}$ rDNA V1-V3 variable regions from 12 swine wastewater lagoon samples. Rarefaction curves were constructed with a $97 \%$ sequence similarity threshold.
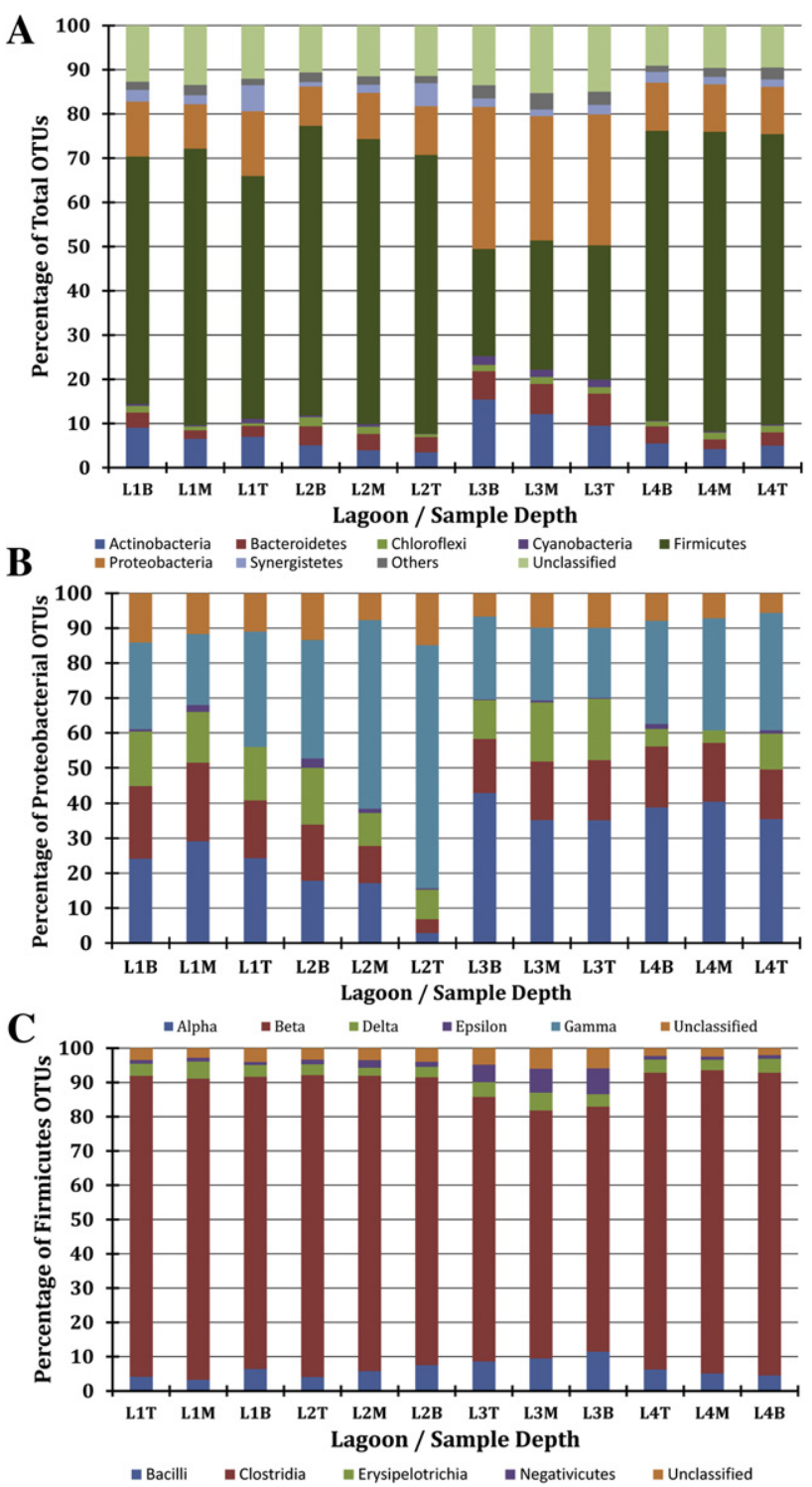

Fig. 2. Relative abundance of bacterial $16 \mathrm{~S}$ rDNA genes from swine wastewater lagoon samples at the phylum level (A), and breakdown of proteobacteria (B), and Firmicutes (C) OTUs as determined by classification using the Ribosomal Database Project (RDP).

$(4.5 \% \pm 1.6)$, Peptostreptococcaceae $(2.2 \% \pm 1.8)$, Synergistaceae $(2.5 \% \pm 1.5)$, and Chromatiaceae $(2.7 \% \pm 1.9)$. For the L3 sites, well represented families also included Syntrophaceae $(1.8 \% \pm 0.5)$, Methylocystaceae $(3.0 \% \pm 0.6)$, Family IIa $(1.6 \% \pm 0.2)$ of the phylum Cyanobacteria, and the Mycobacteriaceae $(1.3 \% \pm 0.4)$.

Wastewater characteristics were collected for each depth from all four lagoons (Table 2). The characteristics of these lagoons were typical of swine anaerobic lagoons found in the mid-South United States $[3,35,36]$. All four lagoons presented as anaerobic, reduced environments, with L3 having an ORP indicative of the potential for denitrification, while the others had values typical of sulfatereduction or methanogenesis. Lagoon $\mathrm{pH}$ was slightly alkaline. For L2, TSS and VSS values were elevated, indicating potential overloading, however both TKN and $\mathrm{NH}_{4}-\mathrm{N}$ values were within typical ranges for swine anaerobic lagoons, indicating proper lagoon function. These data were used in nonmetric multidimensional scaling (NMS) to examine the relationship between the environmental variables and the microbial community structure of each lagoon (Fig. 5). The microbial community profiles taken from 


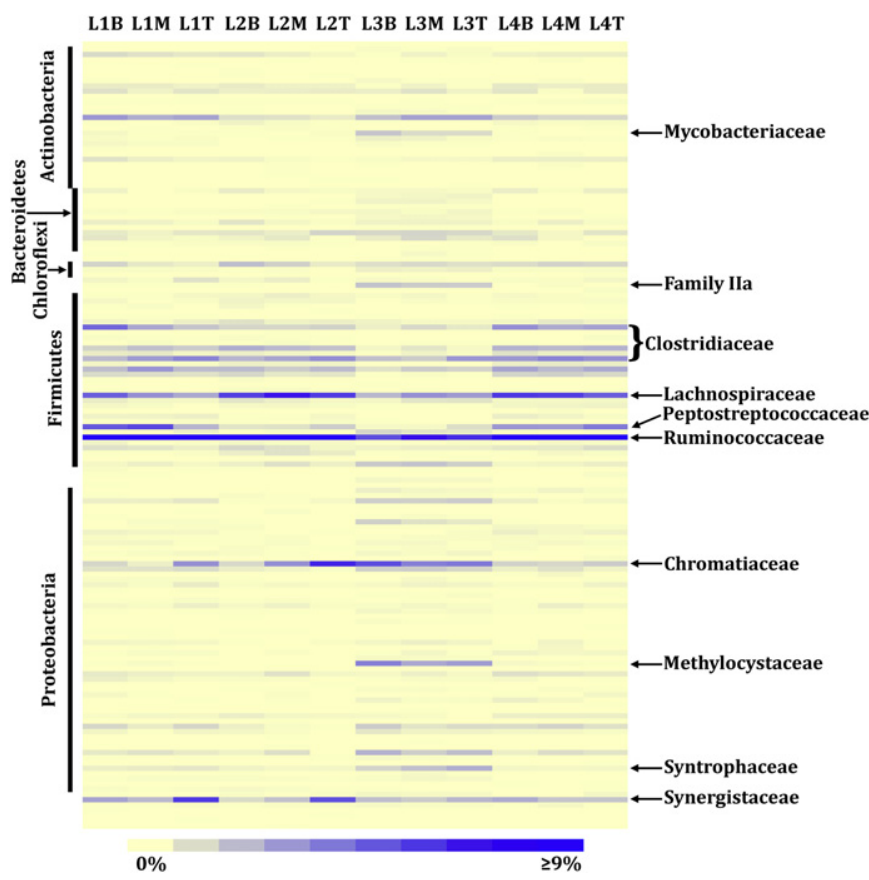

Fig. 3. Heat-map displaying relative abundances of bacterial families. Sites are distinguished by columns, while families are represented as rows. Labeled bars on left of the map indicate different phyla, while specific families are displayed to the right of the map. Color intensity, key provided underneath, indicates the particular families relative abundance in each site. (For interpretation of the references to colour in this figure legend, the reader is referred to the web version of this article.)

each site clustered by lagoon, indicative of lagoon-specific phylotypes distributed throughout the water column. Additionally, a number of relationships between microbial communities and environmental variables were identified. Environmental variables that correlated with community structure were TKN $\left(r^{2}=0.92\right)$, $\operatorname{COD}\left(r^{2}=0.69\right)$, and ORP $\left(r^{2}=0.68\right)$ along the first axis, and TSS $\left(r^{2}=0.49\right)$ and DO $\left(r^{2}=0.48\right)$ along the second axis.

At the genus level, there were 839 genera represented; 223 genera were found in all four lagoons and a total of 321 genera were identified in only one lagoon (Fig. 5). For the four lagoons sampled in this study, the top 25 genera accounted for approximately $20 \%$ of all phylotypes (Table 3). The dominate genera, determined by the relative abundance of classified phylotypes, varied from lagoon to lagoon as follows: L1, Clostridium cluster XI (3.14\%); L2, Thiolamprovum (3.81\%); L3, Methylocystis (2.77\%); L4, Anaerovorax $(2.78 \%)$. The low relative abundances of a majority of the genera suggest that most phylotypes are present at low levels.

\section{Discussion}

Next-generation sequencing (NGS) is rapidly gaining popularity for ecological studies due to its ability to generate data in a cost effective, high-throughput manner. Rather than replace other microbiological and molecular methods, deep 16S rDNA analysis by NGS can provide complementary analysis by identifying members of bacterial communities that were unable to be highlighted by other methods.

For example, studies examining the microbial diversity of anaerobic lagoons [9,37], or alternative swine manure storage systems such as deep pits [11,12], have traditionally utilized either bacterial culture, or the use of clone libraries. These studies however, when compared to the results presented in this study, have identified only a small portion of the organisms inhabiting these

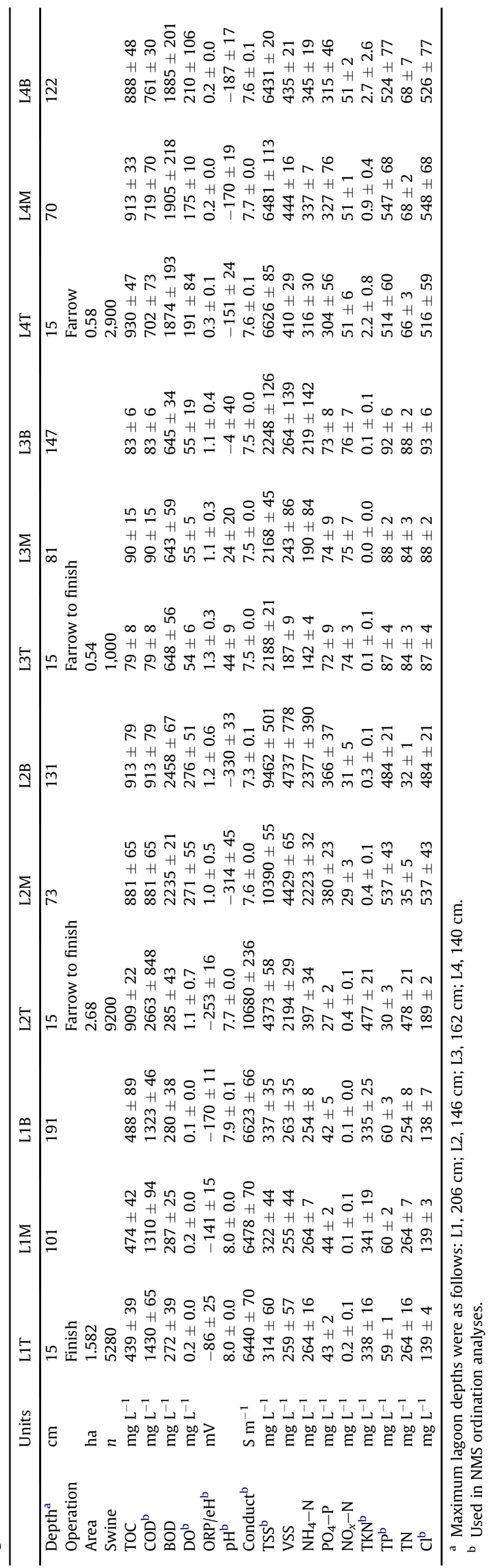


Table 3

Relative abundance (\%) and number of operational taxonomic units (OTUs) of top 25 genera.

\begin{tabular}{|c|c|c|c|c|c|c|c|c|c|}
\hline \multirow[t]{2}{*}{ Phylum } & \multirow[t]{2}{*}{ Genus } & \multicolumn{2}{|c|}{ Lagoon \#1 } & \multicolumn{2}{|c|}{ Lagoon \#2 } & \multicolumn{2}{|c|}{ Lagoon \#3 } & \multicolumn{2}{|c|}{ Lagoon \#4 } \\
\hline & & $\mathrm{Ra}$ & \# OTUs & $\mathrm{Ra}$ & \# OTUs & $\mathrm{Ra}$ & \# OTUs & $\mathrm{Ra}$ & \# OTU \\
\hline Firmicutes & Anaerovorax & $2.58 \%$ & 96 & $2.45 \%$ & 126 & $1.94 \%$ & 73 & $2.78 \%$ & 85 \\
\hline Proteobacteria & Thiolamprovum & $1.59 \%$ & 59 & $3.81 \%$ & 196 & $1.38 \%$ & 52 & $1.14 \%$ & 35 \\
\hline Firmicutes & Clostridium sp. cluster XI & $3.14 \%$ & 117 & $0.70 \%$ & 36 & $0.40 \%$ & 15 & $2.16 \%$ & 66 \\
\hline TM7 & TM7 & $0.89 \%$ & 33 & $1.24 \%$ & 64 & $1.04 \%$ & 39 & $1.34 \%$ & 41 \\
\hline Firmicutes & Clostridium (sensu stricto) & $1.53 \%$ & 57 & $0.64 \%$ & 33 & $0.48 \%$ & 18 & $1.63 \%$ & 50 \\
\hline Firmicutes & Oscillibacter & $0.43 \%$ & 16 & $1.13 \%$ & 58 & $0.85 \%$ & 32 & $0.98 \%$ & 30 \\
\hline Actinobacteria & Leucobacter & $1.67 \%$ & 62 & $0.45 \%$ & 23 & $0.37 \%$ & 14 & $0.78 \%$ & 24 \\
\hline Proteobacteria & Methylocystis & $0.11 \%$ & 4 & $0.10 \%$ & 5 & $2.77 \%$ & 104 & $0.00 \%$ & 0 \\
\hline Firmicutes & Tissierella & $0.67 \%$ & 25 & $0.86 \%$ & 44 & $0.05 \%$ & 2 & $1.18 \%$ & 36 \\
\hline Firmicutes & Acetanaerobacterium & $1.05 \%$ & 39 & $0.56 \%$ & 29 & $0.16 \%$ & 6 & $1.05 \%$ & 32 \\
\hline Firmicutes & Turicibacter & $1.42 \%$ & 53 & $0.40 \%$ & 19 & $0.13 \%$ & 5 & $0.85 \%$ & 26 \\
\hline Firmicutes & Saccharofermentans & $0.67 \%$ & 25 & $0.70 \%$ & 36 & $0.67 \%$ & 25 & $0.33 \%$ & 10 \\
\hline Firmicutes & Lachnospiracea & $0.38 \%$ & 14 & $0.80 \%$ & 41 & $0.56 \%$ & 21 & $0.62 \%$ & 19 \\
\hline Actinobacteria & Corynebacterium & $0.73 \%$ & 27 & $0.52 \%$ & 27 & $0.59 \%$ & 22 & $0.56 \%$ & 17 \\
\hline Firmicutes & Sporobacter & $0.54 \%$ & 20 & $0.76 \%$ & 39 & $0.05 \%$ & 2 & $0.75 \%$ & 23 \\
\hline Synergistetes & Aminobacterium & $0.73 \%$ & 27 & $0.51 \%$ & 26 & $0.24 \%$ & 9 & $0.26 \%$ & 8 \\
\hline Firmicutes & Lactobacillus & $0.38 \%$ & 14 & $0.45 \%$ & 23 & $0.64 \%$ & 24 & $0.29 \%$ & 9 \\
\hline Proteobacteria & Desulfomonile & $0.38 \%$ & 14 & $0.06 \%$ & 3 & $1.23 \%$ & 46 & $0.20 \%$ & 6 \\
\hline Proteobacteria & Acinetobacter & $0.40 \%$ & 15 & $0.45 \%$ & 23 & $0.19 \%$ & 7 & $0.59 \%$ & 18 \\
\hline Actinobacteria & Mycobacterium & $0.13 \%$ & 5 & $0.08 \%$ & 4 & $1.25 \%$ & 47 & $0.03 \%$ & 1 \\
\hline Cyanobacteria & Group IIa & $0.00 \%$ & 0 & $0.00 \%$ & 0 & $1.52 \%$ & 57 & $0.00 \%$ & 0 \\
\hline Actinobacteria & Actinomyces & $0.70 \%$ & 26 & $0.25 \%$ & 13 & $0.11 \%$ & 4 & $0.39 \%$ & 12 \\
\hline Proteobacteria & Thioflavicoccus & $0.00 \%$ & 0 & $0.00 \%$ & 0 & $1.46 \%$ & 55 & $0.00 \%$ & 0 \\
\hline Bacteroidetes & Prevotella & $0.16 \%$ & 6 & $0.27 \%$ & 14 & $0.53 \%$ & 20 & $0.42 \%$ & 13 \\
\hline Actinobacteria & Klugiella & $0.02 \%$ & 1 & $0.00 \%$ & 0 & $1.09 \%$ & 41 & $0.07 \%$ & 2 \\
\hline Total & & $20.30 \%$ & 755 & $17.19 \%$ & 882 & $19.70 \%$ & 740 & $18.40 \%$ & 563 \\
\hline
\end{tabular}

ecosystems. For example, studies by Whitehead and Cotta [12], Cotta et al. [11], Goh et al. [9], and Cardinali-Rezende [37] identified a total of approximately 200 bacterial phylotypes in 60 genera, many of which overlap. In contrast, this study identified 15,682 identified phylotypes, classified into 839 distinct genera. It should be noted however that all the aforementioned studies characterized populations consisting primarily of anaerobic, Gram-positive, low $G+C$ bacteria involved in odor production, fermentation, and nutrient cycling. These studies provide a very important, initial step, into elucidating bacterial community structure and function within these lagoons. However the caveat that presents itself in studies which employ DNA amplification, with or without cloning, is that they are incapable of differentiating between viable and dead organisms [38]. Likewise, even studies relying on culture techniques cannot differentiate between dormant organisms versus those which are actively growing in the environment. These become particular points of concern when dealing with swine production systems, as the animal management practices utilize a variety of antimicrobial compounds which are eventually excreted into swine anaerobic lagoons [39]. In order to address these issues in future studies, we propose utilizing NGS techniques such as metatranscriptomics, to look at the functional microbial populations of anaerobic lagoons [40].

A sizeable body of work has been performed on anaerobic lagoons to identify and quantify organisms responsible for malodorous compounds, in particular hydrogen sulfide $\left(\mathrm{H}_{2} \mathrm{~S}\right)$. Hydrogen sulfide is produced by sulfate-reducing bacteria (SRB) upon the utilization of sulfate as a terminal electron acceptor during the degradation of organic compounds. Cook et al. [15] utilized qPCR and sequencing of the $d s r A$ gene, that encodes for the enzyme dissimilatory sulfite reductase, to determine the abundances and types of SRB in swine manure pits and anaerobic lagoons. Their study utilized primers directed towards SRB from the genera Desulfobacterium, Desulfobulbus, and Desulfovibrio [15]; to date, over 30 known genera of SRB have been characterized [41]. In our study phylotypes were classified to 26 SRB genera, with phylotypes classified to seven SRB genera found in all four anaerobic lagoons. These seven were Desulfatirhabdium, Desulfobulbus, Desulfocurvus, Desulfomonile, Desulfovibrio, Desulfovirga, and Thermodesulfobium. Of the remaining 19, five were identified in three lagoons with Desulfoglaeba, Desulfonispora, and Desulfosporosinus in L1,L 2, and L4, and Desulfatiferula and Desulforegula in L1, L2, and L3. Five additional genera were identified in two lagoons, Desulfobacca and Desulfofaba in L1 and L3, Desulfofustis in L1 and L2, and Desulfococcus and Desulfomicrobium in L1 and L4. Lastly, Desulfarculus (L3), Desulfonema (L1), Desulforhabdus (L3), Desulforhopalus (L3), Desulfospira (L3), Desulfovermiculus (L3), Desulfurispora (L4), Syntrophobacter (L2), and Thermodesulforhabdus (L3) were all identified in a single lagoon. In addition to being an odorous compound, $\mathrm{H}_{2} \mathrm{~S}$ is part of the larger S-cycle, and a number of phylotypes associated with other steps in S-cycling were also detected. These phylotypes were classified as genera known to be involved in the reduction of elemental sulfur (Desulfuromonas, L4), sulfite (Desulfitibacter, L1 and L3), and thiosulfate (Dethiobacter, L2; Dethiosulfatibacter, L1 and L2; and Dethiosulfovibrio, L4).

Examination of the genera identified in this study, and their relative abundances, revealed that the relative abundance of Desulfomonile was higher in L3 as compared to the other lagoons (Table 2). This is interesting because examination of the lagoons anaerobic characteristics, in particular ORP values, suggests that this lagoon is more likely to use nitrate - ORP range of $+50 \mathrm{mV}$ to $-50 \mathrm{mV}$ - to degrade organic compounds as opposed to sulfate [42]. On the other hand, the remaining three lagoons had ORPs in a range $(\leq-50 \mathrm{mV})$ conducive to sulfate-reduction, and concomitantly, $\mathrm{H}_{2} \mathrm{~S}$ production. Earlier studies have demonstrated that anaerobic lagoons undergo mixing of the water column [43], and the abundance of OTUs classified as SRB in L3 may be resultant of this mixing process, as populations from more reduced layers are brought up through the water column. It has also been demonstrated that there is a periodic effect to the chemical makeup of these lagoons [44], with L3 potentially undergoing a slightly less reduced phase. In this case, the SRB may be dormant, only active in 
increasingly anaerobic portions of the lagoon (e.g., sludge layer), while the overall conditions favor denitrification. While such conditions could favor amelioration of lagoon odor, the presence of SRB indicates that a return to more reduced conditions may result in renewed odor production.

In order to produce $\mathrm{H}_{2} \mathrm{~S}$, SRB oxidize a number of endogenously and exogenously produced fermentative products. A number of phylotypes were classified in this study that identify with genera, such as Saccharofermentans [45], that are capable of fermenting numerous carbohydrates. Other organisms, belonging to genera such as Aminobacterium [46], are capable of degrading proteins. Together, these processes produce substrates utilized by SRB during growth. For example, a non-comprehensive list of products include: acetate, butyrate, ethanol, lactate, and propionate. Our study revealed a number of phylotypes classified to genera, also not to be considered comprehensive, known to produce these SRB substrates. The following fermentation products along with genera known for its production were identified in all four lagoons: acetate, Acetanerobacterium, Acetivibrio, and Acetomicrobium; butyrate, Anaerovorax, Butyricicoccus and Butyrivibrio. ethanol, Ethanoligenens; lactate; Lactobacillus and Lactococcus; and propionate, Propionibacterium.

Additionally, acetate can undergo a dismutation reaction by methanogenic archaea to produce methane $\left(\mathrm{CH}_{4}\right)$ and carbon dioxide $\left(\mathrm{CO}_{2}\right)$ [47]. While we did not attempt to identify the archaea in this study, the low redox conditions (see Table 3 ) as indicated by ORP, and the presence of phylotypes classified to several methanotrophic genera, suggest that methanogenesis is occurring to some degree in, if not the water column, then the sludge layer of these anaerobic lagoons. While no phylotypes classified as methanotrophic were found across all four lagoons, Methylocystis (L1, L2, and L3) and Methylohalobius (L1, L2 and L4) were each found in three.

Although a majority of respiration in anaerobic lagoons involves sulfate-reduction or methanogenesis, it has been demonstrated that anaerobic lagoons are also capable of denitrification [7]. This was confirmed in a report by Ducey et al. [6], that quantified the abundance of nitrification and denitrification genes in the water column of eight anaerobic swine wastewater lagoons. They hypothesized that, though redox conditions tend to favor sulfate-reduction and methanogenesis, nitrification and denitrification could potentially occur in select microenvironments, such as the surface-liquid interface, where sufficient oxygen diffusion exists [48]. The identification of significant numbers of nitrifiers in the Ducey et al. study are supported by the identification of genera known to be involved in the oxidation of ammonia $\left(\mathrm{NH}_{3}\right)$ (Nitrosomonas and Nitrosococcus) and nitrite $\left(\mathrm{NO}_{2}\right)$ (Nitrospira) in all four lagoons. Two additional genera, involved in the oxidation of $\mathrm{NH}_{3}$ (Nitrosospira) and $\mathrm{NO}_{2}$ (Nitrobacter) were found in $\mathrm{L} 1$ and L4. These findings are further supported by the preponderance of ammonia oxidizing archaea (AOA) identified in a Brazilian anaerobic lagoon [37].

A cursory examination of the distribution of organisms discussed above, all involved in a variety of biological processes, demonstrates that a significant portion of the microbial community is conserved across lagoons. There remains however, a portion that is specific for each. This observation is reflected both in the NMS (Fig. 4) and Venn diagrams (Fig. 5). These observations also demonstrate that anaerobic lagoons are more microbially diverse that previously understood, though the impact that some of these rare species have in the functioning of anaerobic lagoons remains to be elucidated. Further study also needs to be conducted on the interplay between a lagoons microbial community, and its chemical and nutrient characteristics. These characteristics in turn are controlled by a number of extraneous factors which are reflected in the management principles for each operation. These factors

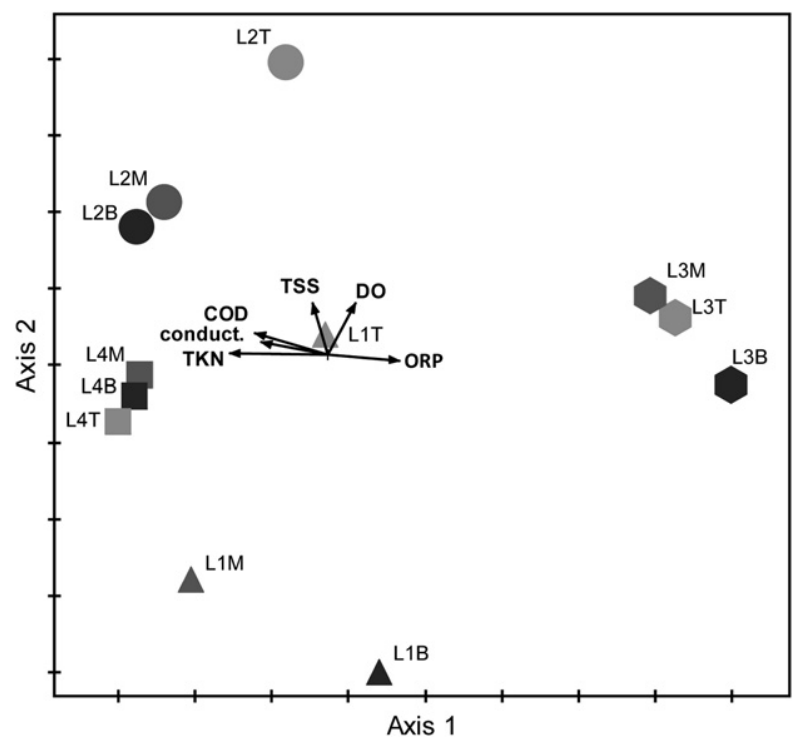

Fig. 4. Nonmetric multidimensional scaling (NMS) plot of microbial communities (based on the relative abundance of bacterial families) identified in the 12 lagoon sites sampled in this study. Only explanatory environmental variables with an $r^{2}>0.5$ are included as vectors. Lagoons are designated by symbol (L1, triangle; L2, circle; L3, hexagon; L4, square), with increasing depth indicated by darkening of the symbol.

include, but are not limited to, differences in the following: dietary supplements and feed [49]; use of antibiotics [1,50]; number of animals [51]; lagoon depth and acreage [52]; and the surrounding soil microbial ecology [53].

Examination of NMS revealed no strong connection between lagoon microbial community structure and operation type. The two lagoons associated with farrow to finish operations (L2 and L3) were separated along the first axis of the NMS ordination, with L2 clustered more closely to lagoons associated with finish (L1) and farrow (L4) operations. The chemical characteristics of these three lagoons were more similar to each other, as compared to L3. It should be noted that L3 was associated with a smaller number of animals and would, as a consequence, receive lower inputs of manure. As mentioned previously, L3, while still anaerobic, was less reduced than the other three lagoons, and also had lower levels of nitrogen (NH4-N, TKN, and TN), suspended solids (TSS and VSS), organic carbon (TOC), oxygen demand (COD and BOD), and EC. Reduced levels of salts, as measured by EC, could be of particular significance. A report by Georgacakis and Sievers reported altered bacterial activity in manure with high concentrations of salt [54],

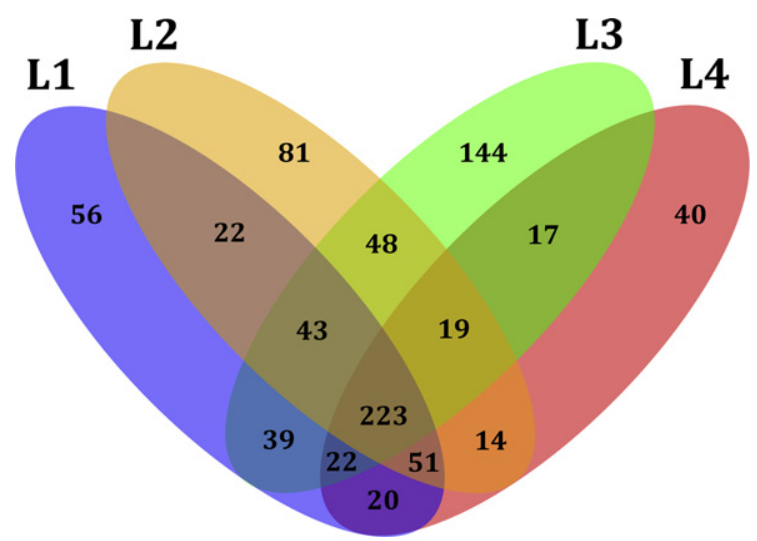

Fig. 5. Venn diagram of all 839 identified genera distributed across the four lagoons examined in this study. 
while McLaughlin et al. reported correlations between EC and levels of certain bacterial groups [3].

The NMS results also indicate that depth was a factor in microbial community composition, though the effect varied from lagoon to lagoon. Analysis of NMS revealed significant separation of the microbial communities at each depth in L1. Conversely, while L2T and L3B clustered loosely with the two remaining depths from their respective lagoons, when compared to the other lagoon samples, they remained most closely related to the samples collected from the same lagoon. Taken together, these results indicate a degree of mixing amongst the lagoon layers, a finding that is supported by previous studies $[5,6]$.

Significant portions of the phylotypes identified were found in relatively low abundances. Despite low relative abundances, such organisms should not be disregarded. These organisms may occupy a specialized niche within the lagoon ecosystem, or they may perform similar or overlapping functions with similarly low proportioned organisms, thereby having a meaningful, cumulative effect. Further studies will need to be performed in order to substantiate either of these hypotheses.

\section{Conclusions}

Similar to other studies examining anaerobic swine wastewater lagoons, our results found a large number of phylotypes that could be classified to organisms that performed functions typical of these ecosystems. These functions include odor production, fermentation, sulfate-reduction, as well as $\mathrm{N}$ - and S-cycling. A majority of the phylotypes represented anaerobic, Gram-positive organisms, with low $\mathrm{G}+\mathrm{C}$ content. A significant portion of the phylotypes identified in this study were found across all four lagoons, but each lagoon did contain its own distinct population.

In 2001, Whitehead and Cotta [12] discussed the potential for a large number of undefined microbial organisms in swine wastewater treatment and storage systems. Since that time however, no studies of a large scope, designed to identify those microbes, have been undertaken. The results of our study constitute a significant and revealing characterization of anaerobic swine wastewater lagoon microbial community structure and diversity.

\section{Acknowledgements}

We thank the members of the Core for Applied Genomics and Ecology at the University of Nebraska at Lincoln, in particular Andrew K. Benson and Jaehyoung Kim, to whom we contracted out the pyrosequencing. We would also like to thank Ariel A. Szogi for technical assistance in the revision of this manuscript. The mention of firm names or trade products does not imply that they are endorsed or recommended by the U.S. Department of Agriculture over other firms or similar products not mentioned.

\section{References}

[1] Brooks JP, McLaughlin MR. Antibiotic resistant bacterial profiles of anaerobic swine lagoon effluent. J Environ Qual 2009;38:2431-7.

[2] Hill VR, Sobsey MD. Performance of swine waste lagoons for removing Salmonella and enteric microbial indicators. Trans ASAE 2003;46:781-8.

[3] McLaughlin MR, Brooks JP, Adeli A. Characterization of selected nutrients and bacteria from anaerobic swine manure lagoons on sow, nursery, and finisher farms in the Mid-South USA. J Environ Qual 2009;38:2422-30.

[4] McLaughlin MR, Brooks JP, Adeli A. Temporal flux and spatial dynamics of nutrients, fecal indicators, and zoonotic pathogens in anaerobic swine manure lagoon water. Water Res 2012;46:4949-60.

[5] Cook KL, Rothrock Jr MJ, Lovanh N, Sorrell JK, Loughrin JH. Spatial and temporal changes in the microbial community in an anaerobic swine waste treatment lagoon. Anaerobe 2010;16:74-82.

[6] Ducey TF, Shriner AD, Hunt PG. Nitrification and denitrification gene abundances in swine wastewater anaerobic lagoons. J Environ Qual 2011;40:610-9.
[7] Hunt PG, Matheny TA, Ro KS, Vanotti MB, Ducey TF. Denitrification in anaerobic lagoons used to treat swine wastewater. J Environ Qual 2010;39: 1821-8.

[8] Sharpe RR, Harper LA, Byers FM. Methane emissions from swine lagoons in Southeastern US. Agr Ecosyst Environ 2002;90:17-24.

[9] Goh SHM, Mabbett AN, Welch JP, Hall SJ, McEwan AG. Molecular ecology of a facultative swine waste lagoon. Lett Appl Microbiol 2009;48:486-92.

[10] Cook KL, Rothrock MJ, Loughrin JH, Doerner KC. Characterization of skatoleproducing microbial populations in enriched swine lagoon slurry. FEMS Microbiol Ecol 2007;60:329-40.

[11] Cotta MA, Whitehead TR, Zeltwanger RL. Isolation, characterization and comparison of bacteria from swine faeces and manure storage pits. Environ Microbiol 2003;5:737-45.

[12] Whitehead TR, Cotta MA. Characterisation and comparison of microbia populations in swine faeces and manure storage pits by 16S rDNA gene sequence analyses. Anaerobe 2001;7:181-7.

[13] Zhu J. A review of microbiology in swine manure odor control. Agr Ecosyst Environ 2000;78:93-106.

[14] Chen T, Schulte DD, Koelsch RK, Parkhurst AM. Characteristics of phototrophic and non-phototrophic lagoons for swine manure. Trans ASAE 2003;46:1285-92.

[15] Cook KL, Whitehead TR, Spence C, Cotta MA. Evaluation of the sulfatereducing bacterial population associated with stored swine slurry. Anaerobe 2008; $14: 172-80$

[16] Shokralla S, Spall JL, Gibson JF, Hajibabaei M. Next-generation sequencing technologies for environmental DNA research. Mol Ecol 2012;21:1794-805.

[17] Bowers RM, Sullivan AP, Costello EK, Collett Jr JL, Knight R, Fierer N. Sources of bacteria in outdoor air across cities in the midwestern United States. Appl Environ Microbiol 2011;77:6350-6.

[18] Fierer N, Lauber CL, Ramirez KS, Zaneveld J, Bradford MA, Knight R Comparative metagenomic, phylogenetic and physiological analyses of soil microbial communities across nitrogen gradients. ISME J 2012;6:1007-17.

[19] Cox-Foster DL, Conlan S, Holmes EC, Palacios G, Evans JD, Moran NA, et al. A metagenomic survey of microbes in honey bee colony collapse disorder. Science 2007;318:283-7.

[20] Yergeau E, Lawrence JR, Sanschagrin S, Waiser MJ, Korber DR, Greer CW. Nextgeneration sequencing of microbial communities in the Athabasca River and its tributaries in relation to oil sands mining activities. Appl Environ Microbiol 2012.

[21] Kuczynski J, Lauber CL, Walters WA, Parfrey LW, Clemente JC, Gevers D, et al Experimental and analytical tools for studying the human microbiome. Nat Rev Genet 2012;13:47-58.

[22] Standard methods for the examination of water and wastewater. 20th ed.Washington, DC: APHA; 1998.

[23] Martinez I, Wallace G, Zhang CM, Legge R, Benson AK, Carr TP, et al. Dietinduced metabolic improvements in a Hamster model of hypercholesterolemia are strongly linked to alterations of the gut microbiota. Appl Environ Microbiol 2009;75:4175-84.

[24] Polz MF, Cavanaugh CM. Bias in template-to-product ratios in multitemplate PCR. Appl Environ Microbiol 1998;64:3724-30.

[25] Kim M, Morrison M, Yu Z. Evaluation of different partial 16S rRNA gene sequence regions for phylogenetic analysis of microbiomes. J Microbiol Methods 2011:84:81-7.

[26] Ahmed N, Huse SM, Ye Y, Zhou Y, Fodor AA. A Core human microbiome as viewed through 16S rRNA sequence clusters. PLoS One 2012;7:e34242.

[27] Wang Q, Garrity GM, Tiedje JM, Cole JR. Naive Bayesian classifier for rapid assignment of rRNA sequences into the new bacterial taxonomy. Appl Environ Microbiol 2007;73:5261-7

[28] Vilo C, Dong Q. Evaluation of the RDP classifier accuracy using 16S rRNA gene variable regions. Metagenomics 2012;1:1-5

[29] Benson AK, Kelly SA, Legge R, Ma F, Low SJ, Kim J, et al. Individuality in gut microbiota composition is a complex polygenic trait shaped by multiple environmental and host genetic factors. Proc Natl Acad Sci USA 2010;107: 18,933-18,938.

[30] Drummond AJ, Ashton B, Cheung M, Heled J, Kearse M, Moir R, et al. In: Geneious. 3.6.2 ed. Auckland (NZ): Biomatters, Ltd; 2007.

[31] Holland SM. In: Analytical rarefaction. 1.3 ed. Athens (GA): University of Georgia; 2003.

[32] Simpson EH. Measurement of diversity. Nature 1949;163:688.

[33] Good IJ. The population frequencies of species and the estimation of population parameters. Biometrika 1953;40:237-64.

[34] Oliveros JC. VENNY: an interactive tool for comparing lists with Venn diagrams; 2007.

[35] Bicudo JR, Safley Jr LM, Westerman PW. Nutrient content and sludge volumes in single-cell recycle anaerobic swine lagoons in North Carolina. Trans ASAE 1999;42:1087-93.

[36] Szogi AA, Vanotti MB. Removal of phosphorus from livestock effluents J Environ Qual 2009;38:576-86.

[37] Cardinali-Rezende J, Pereira ZL, Sanz JL, Chartone-Souza E, Nascimento AM. Bacterial and archaeal phylogenetic diversity associated with swine sludge from an anaerobic treatment lagoon. World J Microbiol Biotechnol 2012.

[38] Maurer JJ. Rapid detection and limitations of molecular techniques. Annu Rev Food Sci T 2011;2:259-79.

[39] Rajic A, Reid-Smith R, Deckert AE, Dewey CE, McEwen SA. Reported antibiotic use in 90 swine farms in Alberta. Can Vet J 2006:47:446-52.

[40] Cardenas E, Tiedje JM. New tools for discovering and characterizing microbial diversity. Curr Opin Biotech 2008;19:544-9. 
[41] Rabus R, Hansen TA, Widdel F, editors. Dissimilatory sulfate- and sulfurreducing prokaryotes. 3rd ed. New York, NY: Springer Science; 2006.

[42] Gerardi MH. In: The microbiology of anaerobic digesters. 1st ed. Hoboken, NJ: Wiley-Interscience; 2003.

[43] Lovanh N, Loughrin JH, Cook K, Rothrock M, Sistani K. The effect of stratification and seasonal variability on the profile of an anaerobic swine waste treatment lagoon. Bioresour Technol 2009;100:3706-12.

[44] Westerman PW, Ogejo JA, Grabow GL. Swine anaerobic lagoon nutrient concentration variation with season, lagoon level, and rainfall. Appl Eng Agric 2010;26:147-52.

[45] Chen S, Niu L, Zhang Y. Saccharofermentans acetigenes gen. nov., sp. nov., an anaerobic bacterium isolated from sludge treating brewery wastewater. Int Syst Evol Microbiol 2010;60:2735-8.

[46] Baena S, Fardeau ML, Labat M, Ollivier B, Garcia JL, Patel BK. Aminobacterium mobile sp. nov., a new anaerobic amino-acid-degrading bacterium. Int J Syst Evol Microbiol 2000;50(Pt 1):259-64.

[47] Daniels L, Sparling R, Sprott GD. The bioenergetics of methanogenesis. Biochim Biophys Acta 1984;768:113-63.
[48] Ro KS, Hunt PG, Poach ME. Wind-driven surficial oxygen transfer and dinitrogen gas emission from treatment lagoons. J Environ Sci Heal A 2006;41:1627-38.

[49] Sutton AL, Kephart KB, Verstegen MW, Canh TT, Hobbs PJ. Potential for reduction of odorous compounds in swine manure through diet modification. J Anim Sci 1999;77:430-9.

[50] Looft T, Johnson TA, Allen HK, Bayles DO, Alt DP, Stedtfeld RD, et al. In-feed antibiotic effects on the swine intestinal microbiome. Proc Natl Acad Sci USA 2012;109:1691-6.

[51] Chinivasagam HN, Thomas RJ, Casey K, McGahan E, Gardner EA, Rafiee M, et al. Microbiological status of piggery effluent from 13 piggeries in the south east Queensland region of Australia. J Appl Microbiol 2004;97:883-91.

[52] Parker CD. Biological mechanisms in lagoons. Prog Water Technol 1979;11: 71-85.

[53] Godon JJ, Moriniere J, Moletta M, Gaillac M, Bru V, Delgenes JP. Rarity associated with specific ecological niches in the bacterial world: the 'Synergistes' example. Environ Microbiol 2005;7:213-24.

[54] Georgacakis D, Sievers DM. Bacterial response to salts in an anaerobic dairy lagoon. Trans ASAE 1979;22:162-93. 